Ad Hoc Advisory Group's proposals for research ethics committees

\section{The Ad Hoc Advisory Group's proposals for research ethics committees: a mixture of the timid, the revolutionary, and the bizarre}

\section{A J Dawson}

\section{The Report of the Ad Hoc Adivisory Group on the Operation of NHS Research Ethics Committees has resulted in a strange mixture of the timid, the revolutionary, and the bizarre.}

$\mathrm{T}$ he Report of the Ad Hoc Advisory Group on the Operation of NHS Research Ethics Committees (AHAG) is a curious document. ${ }^{1}$ The remit of the review was focused on the workings and effectiveness of NHS research ethics committees (both the local committees (LRECs) and the multicentre committees (MRECs)). The Group was primarily set up in response to a series of complaints from medical researchers about the new research governance regime in the UK as a result of the Clinical Trials Directive ${ }^{2}$ and the Governance Arrangements for NHS Research Ethics Committees. ${ }^{3}$ The opportunity was also taken to consider the role of research ethics committees in a wider context, and take account of recent developments in relation to the ethics review of social care research, ${ }^{4}$ student projects, ${ }^{5}$ as well as recent legislation such as the Human Tissue Act, ${ }^{6}$ and the Mental Capacity Act. $^{7}$ However, the resulting report is a strange mixture of the timid, the revolutionary, and the bizarre.

A good example of the report's timidity is its reluctance to propose fundamental change to the process of review or seriously limit the type of research that requires REC review. To its credit AHAG does suggest that some research 'especially surveys and many studies on NHS staff, could normally be conducted safely without a requirement for REC review' (section 3.1). ${ }^{1}$ This is, of course, to be welcomed. However, the report ultimately seems dismissive of the general complaint from researchers that the current process is inappropriately uniform. For example, in section 3.2, it is argued that the 'common perception that the NHS REC system is dominated by the review of clinical trials' is a mistake. This claim is supported by the statistic that only $15 \%$ of applications are for such trials. However, this misses the point. The objection is to the fact that the system and the application form are designed with clinical trials in mind. Even if this system is appropriate for clinical trials, and this might be doubted, ${ }^{8}$ it is not clear that the same system is appropriate for all types of research.

In essence, AHAG fails to acknowledge the diversity of research that comes before NHS committees. Given this diversity, it is not clear that one form, one process, and one committee structure is appropriate. Rather, the review of research ought to be proportionate to the possibility of harm resulting from the research and should seek to balance siderations. Whilst it must be acknowledged that research may cause harm, the current system does not seem to recognise that such risks differ to a significant degree depending upon the nature of the study and the methodology employed. Currently, the degree of ethics review and scrutiny is not correlated with the degree of risk to participants. Research must go to an NHS REC if the research falls into particular categories-for example, if it involves NHS patients, NHS staff, or is carried out on NHS property-whatever the risk of harm. As a result some research with a serious potential risk of harm does not need NHS review even when it has potential clinical application-for example, a piece of physiology research into the affects of reduced oxygen intake conducted in a university-whereas some health care research with a very low risk of harm does need to be reviewed-for example, a nurse talking to her colleagues about their attitudes to a series of ethical issues.

Presumably this reluctance to consider more wide-ranging reform for the review process is a result of AHAG's acceptance that the current system is any possible harm against other con- the best way to prevent harm to research participants. What is strange about this is the apparent unwillingness to judge potential benefits from research along with those possible harms. Surely, any such review of research should begin with an acknowledgement of the benefits that much clinical research brings? If you look for this in the AHAG Report you will be disappointed. While the report notes the importance of promoting 'research of real value' (section 2.6) it never mentions the benefits that might come from clinical research, such as the reduction in mortality as a result of research into childhood cancer. ${ }^{9}$ AHAG seem to miss the idea that whilst research ethics committees should take the risk of harm seriously, they should balance it against other considerations. Sometimes these other considerations should take priority. ${ }^{10}$

This same attitude was also visible in the earlier Doyal Report recommending the adoption of Student Project Ethics Committees (SPECs). ${ }^{5}$ That report fails to take seriously the benefits to us all from having suitably trained health care researchers, and the need for them to be involved in clinical research at an early stage in their careers. Instead, Doyal's central claim is that student projects are not primarily about the production of research but the training and/or education of the student-researchers. They suggest that this means that such 'research' potentially breached the Declaration of Helsinki as the benefits of the research to the participants do not clearly outweigh any risk of harm. ${ }^{11}$ However, an alternative conclusion would be that it is inappropriate to use Helsinki to judge student projects, as they are not medical research and do not, generally, pose the dangers to patients that may result from, say, drug trials. A second year medical student project asking ten people with diabetes about their quality of life does not need to be dealt with in a similar way to a randomised controlled trial funded by a large pharmaceutical company. It is vital that governance arrangements are proportionate to the risk of harm likely to result from the proposed intervention.

Unfortunately, AHAG seem to support the move towards the creation of SPECs, although their exact intentions (in point 13, appendix 3) are rather opaque. What is clear is their support for separate new committees to review phase 1 trials and social care research. No clear justification is given for this multiplication of committees, and it is striking that they will all to be based around different categories of research, rather than related to any potential degree of risk related to the research 
I suggested above that the AHAG Report was a mixture of the timid, the revolutionary, and the bizarre. I end with a short mention of the revolutionary and the bizarre. An excellent example of a revolutionary proposal, tucked away at the back of the report, is the suggestion to move towards a fully professionalised research ethics committee workforce. This momentous proposal for change receives little in the way of supporting argument. Nor is there any discussion of potential drawbacks. How is anyone supposed to fit such a role with a full time job? Are researchers going to be happy that their work is reviewed by people paid to do so? Are research participants going to trust review by an ethics committee that has been paid? Revolutionary proposals require thorough discussion and a sound cost-benefits analysis, not just a quick sketch at the end of a short report.

An example of the bizarre is AHAG's startling claim that, 'RECs should not reach decisions based on scientific review' (Recommendation 2). Presumably, they mean that RECs should not conduct their own ad hoc scientific review, but accept in good faith the scientific peer review provided with the application. However, such a view seems very odd. Surely a study's methodology can raise ethical issues? Is it not an ethical issue if the study will fail to answer the research questions set by the researcher? As anyone who has sat on a REC knows these are, rightly, serious concerns for many members of RECs. The review process will be poorer and perhaps even impossible if this discussion is now to be banned. The tidy separation between scientific and ethical review envisaged here is impossible. What is interesting is that this bizarre claim receives no justification. This is typical of the way that many parts of the Report are seriously under-argued.

In conclusion, much discussion of issues in research ethics tends not to seek to balance all relevant considerations. Certain types of research currently require elaborate review, even when they are unlikely to cause any harm. Other projects, whilst more likely to bring about harm, do not need to be reviewed. AHAG missed an opportunity to redress this issue and correlate the degree of risk with the rigor of review. Whether this is done through the construction of different committees or different applications forms for the same committee is open to debate, but something needs to change in the system. AHAG should have taken the views of researchers more seriously. In other respects the Report is revolutionary. Where such proposals are made we are surely due a full and balanced discussion. On the bizarre elements, let's be charitable, and just be silent.

J Med Ethics 2005;31:435-436.

doi: 10.1136/jme.2005.013250

Correspondence to: A J Dawson, Centre for Professional Ethics, Keele Hall, Keele University Staffs, ST5 5BG, UK; a.j.dawson@keele.ac.uk; Website: www.keele.ac.uk/ethics

Competing interests: A J Dawson is a member of the Shropshire Local Research Ethics Committee. The views expressed in this article are purely the author's own. The author has been involved in training the members of research ethics committees and individuals with responsibility for research ethics and research governance in higher education as part of his employment at Keele University.

Ethical approval was not required.

\section{REFERENCES}

1 Report of the Ad Hoc Advisory Group on the Operation of NHS Research Ethics Committees. Department of Health. 2005. hitp:// www.dh.gov.uk/assetRoot/04/11/24/17/ 04112417.pdf (Accessed 18/6/05)

2 Directive 2001/20/EC of the European Parliament and of the Council of 4 April 2001. http://europa.eu.int/eur-lex/pri/en/oj/dat/ 2001/I_121/I_12120010501en00340044.pdf.

3 Department of Health. Research Governance Framework for Health and Social Care. Department of Health Publications. March 2001 London. http://www.dh.gov.uk/assetRoot/04/ 01/47/57/04014757.pdf.

4 Ethics review of social care research: Options appraisal and guidelines. Department of Health 2004

5 The Ethical Governance and Regulation of Student Projects: a draft proposal. COREC 2004. http://www. corec.org.uk/recs/docs/ SPECs_proposal_DRAFT.doc (Accessed 18/6) 05).

6 Human Tissue Act. 2004. http:// www.opsi.gov.uk/acts/acts2004/ 20040030.htm [accessed 18/6/05]

7 Mental Capacity Act. 2005. http:// www.opsi.gov.uk/acts/acts2005/ 20050009.htm (Accessed 18/6/05).

8 Glasziou P, Chalmers I. Ethics Review Roulette: what can we learn? BMJ 2004;328:121-122.

9 Stiller CA, Bunch KJ. Trends in survival for childhood cancer in Britain diagnosed 1971-85. Br J Cancer 1990;62:806-815.

10 Garrard E, Dawson AD. What is the role of the REC? Paternalism, inducements and harm in research ethics. J Med Ethics 2005;31:419-423.

11 World Medical Association Declaration of Helsinki. Ethical Principles for Medical Research Involving Human Subjects. Edinburgh, Scotland: 52nd WMA General Assembly, October 2000, with clarification 2002, http://www.wma.net/e/ policy/b3.htm (Accessed 18/6/05). 